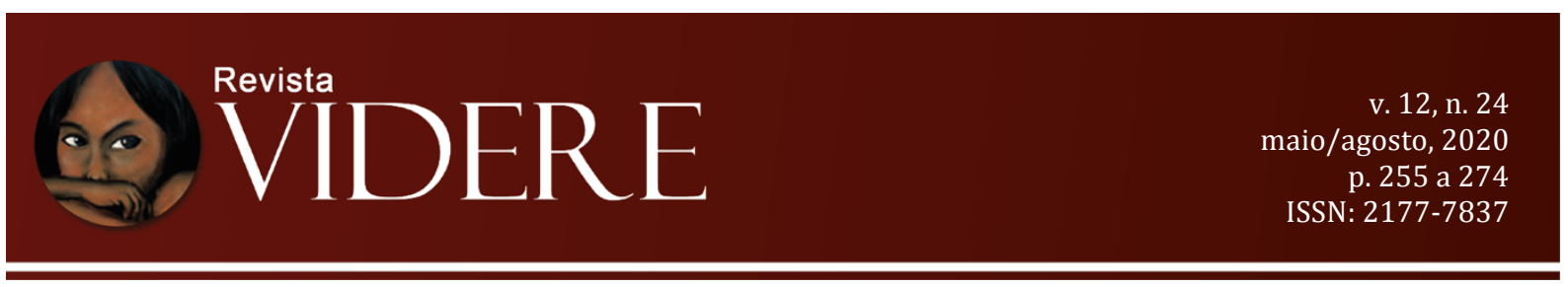

\title{
A DIFICULDADE DA TOLERÂNCIA NO DIÁLOGO ENTRE CONSERVADORISMO FUNDAMENTALISTA E A LUTA PELOS DIREITOS LGBT+
}

\author{
THE DIFICULTY OF TOLERANCE ON THE DIALOGUE BETWEEN \\ FUNDAMENTALIST CONSERVATISM AND FIGHT FOR LGBT+ RIGHTS
}

\author{
Arísio Antonio Fonseca Junior \\ Mestre em Direito (UFOP), Brasil \\ E-mail: arisiofonsecajr@gmail.com \\ OrcID: https://orcid.org/0000-0002-1758-5581
}

\author{
Bruno Camilloto \\ Doutor em Direito (PUC-MG), Brasil \\ Mestre em Direito (UFMG), Brasil \\ Professor da Universidade Federal de Ouro \\ Preto (UFOP), Brasil \\ E-mail: brunocamilloto@ufop.edu.br \\ OrcID: https://orcid.org/0000-0003-4067-4272
}

RESUMO: Após democráticos debates ocorridos na Assembleia Nacional Constituinte, foi promulgada a Constituição da República, consubstanciando em seu texto valores, princípios e direitos plurais. Normativamente, ela tornou-se o parâmetro político e moral da produção normativa e da construção da sociedade, em que os direitos fundamentais apresentam-se como limites para os discursos jurídico e político. Nesse contexto, a crescente onda conservadora fundamentalista notadamente no Congresso Nacional coloca em risco o projeto constitucional de igualdade e liberdade de minorias. Especificamente, as pessoas LGBT+ sofrem com a ofensiva conservadora do Parlamento, salientando a dificuldade da tolerância em relação às propostas legislativas de uso dos sistemas jurídico e político institucionais para restrição de direitos fundamentais daquela minoria.

PALAVRAS-CHAVE: Tolerância. Liberalismo político. Direitos de minorias. LGBT+. Conservadorismo fundamentalista.

ABSTRACT: After democratic debates in the National Constituent Assembly, the Constitution of Republic was promulgated, embodying in its text plural values, principles and rights. Normatively, it has become the political and moral parameter of normative production and of the construction of society, in which fundamental rights present themselves as limits for legal and political discourses. In this context, the growing fundamentalist conservative wave notably in the National Congress puts at risk the constitutional project of equality and freedom of minorities. Specifically, LGBT + people endure Parliament's conservative offensive, stressing the difficulty of tolerance over legislative proposals to use institutional and legal systems to restrict the fundamental rights of that minority. 
KEYWORDS: Tolerance. Political liberalism. Rights of minorities. LGBT+. Fundamentalist conservatism.

\section{Introdução}

O pluralismo é uma característica de muitas sociedades e Estados na contemporaneidade. A sociedade brasileira encontra-se nesse contexto, sendo composta de inúmeros e distintos grupos, variadas concepções privadas e coletivas de boa vida, incontáveis formas de estar no mundo ${ }^{125}$. A coexistência entre tantas possibilidades de exercer a liberdade individual dificilmente acontece sem embates, confrontações ou disputas pelos sentidos normativos que deverão reger os comportamentos humanos e as concepções de vida boa no interior da convivência social.

No âmbito de um Estado Democrático de Direito, que pressupõe a preservação de distintas concepções normativas de vida boa, a dificuldade de uma convivência pacífica e estável entre todas aquelas concepções, com mais razão, se mostra evidente, visto que, no jogo democrático do poder político, pessoas e grupos representativos de determinada concepção de bem podem pretender utilizarem-se das instituições públicas para fazer prevalecer suas concepções sobre aquelas minoritárias.

A situação das pessoas LGBT+ ante as composições muito conservadoras do atual Congresso Nacional brasileiro salienta esse problema. Entende-se, neste texto, essa perspectiva conservadora como fundamentalista à medida que explicita um modo de pensar e de agir contrário à tradição ocidental consagrada pela teoria dos direitos humanos e consignada na Constituição da República de 1988 (doravante mencionada apenas como Constituição ou Constituição da República) como direitos fundamentais. Esse conservadorismo fundamentalista baseia-se na existência de uma única verdade, cujo fundamento é a revelação divina, que impede, por isso, a possibilidade da discussão sobre temas em termos políticos, plurais e democráticos.

A fim de se discutir a questão do não reconhecimento dos sujeitos LGBT+ pelo Direito brasileiro, parte-se para uma tentativa de operacionalizar um conceito de tolerância para observar se a omissão parlamentar em legislar em proveito daquele grupo é admissível (ou tolerável). No contexto atual do Brasil, a Constituição da República apresenta-se como o

\footnotetext{
${ }^{125} \mathrm{O}$ conceito de vida boa é interpretativo e depende do contexto de linguagem no qual está sendo mobilizado. Ele faz parte do contexto e das compreensões sociais de uma determinada época. Para os objetivos desse trabalho, vida boa significa a possibilidade de cada indivíduo eleger seus valores de vida, comportando-se de acordo com eles. Numa sociedade pluralista, deve haver espaço e proteção suficientes para diferentes projetos de vida. Para aprofundamento sobre o tema nas perspectivas jurídica e filosófica, ver Dworkin (2011).
} 
referente normativo-jurídico para se avaliar a postura não só dos particulares, mas também, e notadamente, dos poderes constituídos. Portanto, pretende-se com este texto, tanto problematizar a questão do embate entre conservadorismo fundamentalista e os direitos dos LGBT+, quanto utilizar um conceito de tolerância para demonstrar que é possível não se tolerar o discurso religioso-parlamentar para impedir a fruição de direitos das pessoas LGBT+ como partes livres e iguais da sociedade brasileira.

Desse modo, o texto parte da constatação do fato do pluralismo, especialmente a partir da Constituição, que foi promulgada após abundantes debates na Assembleia Nacional Constituinte e orientada por diversas formas de visão de mundo. Em seguida, anota-se o ressurgimento de vozes conservadoras no Congresso Nacional, cujas agendas orientam a política de forma a se contrapor, em algumas situações normativas, aos direitos fundamentais constitucionais. Vista essa tensão entre o pluralismo político constitucional e o conservadorismo fundamentalista, surge a necessidade de se trabalhar com a ideia de tolerância como instrumento de compreensão sobre a compatibilidade entre visões de mundo específicas e direitos fundamentais de grupos minoritários. Neste ponto, o grupo em perspectiva é aquele composto por pessoas LGBT+, cujos direitos fundamentais são ou negligenciados, ou negados por um Congresso Nacional amplamente permeado por concepções religiosas fundamentalistas. Por fim, faz-se uma análise para saber se é possível um diálogo com base na tolerância entre a luta pelos direitos das pessoas LGBT+ e a postura fundamentalista conservadora parlamentar.

\section{O fato do pluralismo nos marcos da Constituição da República}

Inicialmente, importante considerar que a Constituição da República foi promulgada após inúmeros debates entre setores da sociedade civil. Fruto da transição entre um período de autoritarismo civil-militar e das demandas por redemocratização, a Constituição estabeleceu um novo panorama no constitucionalismo brasileiro. Nas comissões e subcomissões da Assembleia Nacional Constituinte, propostas de redação, pretensões de direitos, demonstrações de interesses foram levadas tanto pelos representantes, quanto pelo povo por meio de associações e órgãos de classe. As discussões que se realizaram naqueles momentos de produção constitucional tiveram como participantes membros de variadas perspectivas políticas, ideológicas, filosóficas e religiosas, conformando um texto basilar analítico e, ao mesmo tempo, democrático (PINTO, 2009, p. 79-85).

A riqueza da pluralidade consignada na Constituição é compreendida por Bonavides e Andrade (2008, p. 502-503) em dois momentos: o primeiro de estabelecimento 
das normas constitucionais que explicitam o projeto de sociedade plural e democrática desejada pela sociedade; o segundo de aplicação e efetivação daquele projeto constitucional aprovado pelo Poder Constituinte originário, especialmente quando pensado a partir da necessidade de regulamentação infraconstitucional a ser realizada pelo Poder Legislativo constituído:

O conteúdo pluralista e não raro contraditório de compromisso consensual obtido mediante a aprovação do texto inculca já, para efeito de eficácia, a importância da segunda fase, menos ruidosa, sem dúvida, mas não menos crucial, em que se concretizará nas leis ordinárias e complementares a outra metade da Constituição, aquela que não consta formalmente do texto aprovado, ou seja, a Constituição regulamentada para aplicar-se e positivarse e que não dispensa tampouco o formalismo, embora seja este de grau inferior, e que, em compensação, se dirige nos seus preceitos à realidade, isto é, esfera das relações concretas a serem reguladas por força e extensão dos próprios mandamentos constitucionais estabelecidos. (BONAVIDES; ANDRADE, 2008, p. 503).

Normativamente, a Constituição adotou valores, princípios e objetivos fundamentais, diretrizes políticas de fundo moral ${ }^{126}$, a fim de guiar a orientação e a interpretação de si própria e das leis que a ela se submetem. Politicamente liberal ${ }^{127}$, portanto, a Constituição da República torna-se o centro de integração da sociedade, verdadeiro padrão deontológico a partir do qual as divergências jurídico-políticas devem apoiar-se para obter resoluções que "favoreçam a integração política e social, produzindo um efeito criador e conservador da unidade", conforme o princípio do efeito integrador da hermenêutica

\footnotetext{
${ }^{126}$ A ideia de fundo moral aqui apresentada se vincula à ideia do "consenso sobreposto" exposta por Rawls (2006, p. 173), segundo a qual "ese consenso se compone de doctrinas comprehensivas razonables que probablemente persistirán y ganarán adhesiones con el transcurso del tiempo y en el marco de una estructura básica justa (según la definición de la concepción política)". Esse consenso de doutrinas abrangentes razoáveis, portanto, tornaria a sociedade bem-ordenada estável e permitiria que os cidadãos desenvolvessem suas vidas conforme suas próprias concepções éticas. Assim, prefere-se pensar que a Constituição da República não se trata de um caso de "consenso constitucional", visto que este "no es profundo, ni tampoco es amplio: es de corto alcance, no incluye la estructura básica, sino sólo los procedimientos políticos de un gobierno democrático" (Rawls 2006:191). Para os fins argumentativos deste trabalho, entende-se a Constituição da República como um "consenso sobreposto", mormente em razão do caráter dissensual e eticamente plural dos debates da e na Assembleia Nacional Constituinte. Em posição contrária, Rocha (2009, p. 304), que afirma que "Rawls admite que há, nos Estados Unidos, algo parecido com um consenso constitucional. Se os EUA, um país que goza de singular estabilidade constitucional, cujo cenário político, se comparado aos demais países do Ocidente, praticamente padece de um monismo ideológico, alcançaram apenas o consenso constitucional, que dizer dos territórios conflagrados da África, Ásia, Europa e América Latina?".

${ }^{127}$ Em Rocha (2009), vê-se que ele contrapõe parcelas do texto constitucional como caracterizadas pelo comunitarismo, enquanto outras expressões da Constituição podem ser observadas como politicamente liberais. Em um ponto em comum entre essas correntes, o autor encontra "a superação de todo o reducionismo do direito ao positivismo, seja ele normativo, seja sociológico, pelo reconhecimento da necessidade de um direito constitucional moralmente reflexivo" (ROCHA, 2009, p. 310). É neste aspecto do uso da razão pública na construção de uma sociedade moralmente reflexiva num contexto de pluralidade de ideias que se entende a Constituição como politicamente liberal.
} 
constitucional (NOVELINO, 2016, p. 136). Exemplificativamente, o art. $1^{\mathrm{o}}, \mathrm{V}$, da Constituição prevê o pluralismo político como fundamento da República; já o art. $3^{\circ}$, IV dispõe que é objetivo fundamental do Brasil "promover o bem de todos, sem preconceitos de origem, raça, sexo, cor, idade e quaisquer outras formas de discriminação"; assim como o art. $5^{\circ}$, caput dispõe que "[t]odos são iguais perante a lei, sem distinção de qualquer natureza, garantindo-se aos brasileiros e aos estrangeiros residentes no País a inviolabilidade do direito à vida, à liberdade, à igualdade, à segurança e à propriedade”. Esses são, assim, exemplos de normas constitucionais que sustentam um padrão mínimo de consenso social, as quais exigem sua observância quando haja disputas por alterações nas instituições e nas questões de justiça $^{128}$.

De extrema relevância dentre os princípios fundadores está aquele disposto no caput do art. $1^{\circ}$ da Constituição, que estabelece constituir-se a República Federativa do Brasil em Estado Democrático de Direito. Muito se há escrito sobre esta expressão, atribuindo-se-lhe o caráter de essencialidade dos Estados contemporâneos - ao menos no Ocidente. A importância, porém, que se pretende notar encontra-se no liame entre os dois últimos termos componentes da expressão. Apenas para ficar nas ideias mais consensuais sobre o tema, vê-se que, embora aparentemente paradoxal, a relação existente entre direito e democracia - ou constituição e democracia - pode ser compreendida quando se pensa o nexo entre autonomia pública (soberania popular) e autonomia privada das pessoas (direitos fundamentais) ${ }^{129} 130$. A conjugação do exercício dessas duas autonomias no campo político proporciona o entendimento de como se pode conciliar a regra da maioria com um rol de direitos. De fato, em algum ponto de encontro das ideias dos autores que pensam sobre o tema, a constituição aqui, especialmente, os direitos fundamentais - e a democracia se vinculam de forma a se implicarem reciprocamente. Assim, deliberações de maiorias provisórias no Estado Democrático de Direito - ou seja, o exercício da soberania popular representativa ou diretamente - devem ser limitadas pelos direitos fundamentais, os quais são a manifestação do reconhecimento recíproco entre os cidadãos da dignidade humana, da liberdade e da

\footnotetext{
${ }^{128}$ Em seu texto que analisa a Constituição comparativamente ao modelo liberal de John Rawls e ao modelo comunitarista de Estado e constituição, Rocha (2009, p. 308) assim se manifesta: "Mas se é certo que pluralismo na constituição brasileira tem essa dimensão coletiva, não menos correto reconhecer a sua preocupação em permitir o desenvolvimento da multiplicidade de concepções individuais acerca do bem, como se vê do art. $3^{\circ}$, inciso IV, e do extenso rol do art. $5^{\circ}$, muitos deles garantidores do livre desenvolvimento e expressão individuais".

${ }^{129}$ Essa tensão pode ser compreendida a partir das históricas concepções de Locke (autonomia individual) e Rousseau (soberania popular).

130 Sobre essa relação, Forst (2010), Habermas (2003a, 2003b), Pinto (2009), Rawls (2006), exemplificativamente.
} 
igualdade. A propósito, no Brasil, é a própria Constituição que estabelece essa limitação ao exercício da soberania, quando, no art. $60, \S 4^{\circ}, \mathrm{IV}$, os direitos e garantias individuais erigemse como limitação material ao poder constituinte derivado.

\section{A emergência do conservadorismo fundamentalista}

Ainda que a Constituição da República tenha o nítido caráter liberal politicamente $^{131}$ - e explicite princípios e valores progressistas, desde sua promulgação temse observado o (res)surgimento de pretensões contestadoras - para não dizer contrárias - aos direitos fundamentais e às liberdades públicas de boa parte dos brasileiros. Se, por um lado, o próprio texto constitucional permitiu a expressão das inúmeras possibilidades de o indivíduo se manifestar em diversas perspectivas existenciais (como, p. ex., em relação às distintas concepções de família, ao exercício da sexualidade, às questões afetas à concepção de gênero, etc.), realizando, assim, seus projetos de vida boa; por outro, o próprio exercício da liberdade de expressão na arena pública de discussão trouxe a possibilidade do (re)aparecimento de um discurso conservador fundamentalista quanto ao exercício da moralidade por parte dos indivíduos.

Com base naquilo que Almeida chamou de "onda conservadora", "consolidaramse nos últimos anos forças que trabalham a favor da contenção, da restrição e do retrocesso de alguns direitos garantidos com a promulgação da Constituição de 1988” (2017, não paginado). Segundo esse autor, não é possível apontar um entendimento homogêneo sobre essa "onda", visto que "a pauta conservadora vai além da pauta dos evangélicos conservadores. Dela participam também católicos, outras religiões e não religiosos”, ou seja, "um emaranhado de vários jogadores em diferentes tabuleiros" (ALMEIDA, 2017, não paginado).

Já em 2004, Nishimura (2004, p. 340), em pesquisa realizada após a eleição presidencial de 2002, concluiu que "os resultados aqui observados indicam uma presença expressiva de opiniões e atitudes conservadoras na dinâmica do cotidiano da sociedade brasileira, dificultando significativamente o processo de democratização das relações sociais". Com um recorte temporal diferente, a força dessa onda também foi percebida por Miguel

\footnotetext{
${ }^{131}$ Variados manuais e cursos de Direito Constitucional no Brasil deixariam esta afirmação invalidada se se levasse em conta apenas o confronto entre os paradigmas do Estado Liberal clássico, o Estado de Bem-Estar Social e o Estado Democrático de Direito. Contudo, sustenta-se ter a Constituição da República um caráter liberal no sentido do liberalismo político. Quer-se dizer com isso que ela é fruto de um consenso sobre os fundamentos da justiça social, baseada na liberdade e na igualdade. É no entendimento de que houve o uso da razão pública na formação do texto constitucional, ouvidas as diversas vozes que dialogavam sobre o conteúdo da Constituição, que se tenciona dizer que ela possui característica liberal, cujo fundamento é a preservação de uma sociedade plural do ponto de vista moral.
} 
(2016, p. 592), que afirma que, a partir dos anos 2010, houve um avanço do conservadorismo, “[cujos] discursos reacionários provêm, no caso brasileiro, de uma conjugação heteróclita entre o 'libertarianismo', o fundamentalismo religioso e o antigo anticomunismo". Assim como Miguel, também Carvalho e Sivori (2017) percebem o avanço da agenda conservadora sobre a área da educação, em que o Movimento Escola Sem Partido (MESP) juntamente com o Instituto Millenium combatem a chamada "ideologia de gênero".

É claro que o conservadorismo não atua em uma só frente nem se manifesta numa só direção. Conforme expôs Almeida (2017), a onda conservadora desenvolve-se em "quatro linhas de força" na conjuntura atual: uma, econômica, pela qual "se no nível individual o discurso religioso procura gerar disposição para o empreendedorismo, no plano da política institucional, muitos agentes políticos evangélicos militam declaradamente por uma agenda liberal" (2017, não paginado); outra, moral, em que tanto católicos, quanto protestantes especialmente os evangélicos neopentecostais - pretendem legislar sobre "a moralidade pública para maior controle dos corpos, dos comportamentos e dos vínculos primários" (2017, não paginado); ainda há a securitária, em "uma série de movimentações políticas, demandas coletivas, medidas governamentais que apontam para postura e ações mais repressivas e punitivas dos aparelhos de segurança do Estado" (2017, não paginado); e, por fim, a interacional, em que manifestações de vingança, ódio e fobia entre pessoas podem ser entendidas como "sintoma de afetos sociais mais amplos que são pouco abertos às diferenças, muito voltados sobre si como medida para a vida pública" (2017, não paginado).

Importante observar que, embora analiticamente divida em quatro linhas de força, essa onda conservadora manifesta-se pela articulação dos atores políticos nos parlamentos, cujos interesses ora podem derivar da religião, ora da economia, ou, ainda, da combinação de ambas com o propósito de manter um status de violação dos direitos fundamentais. Como afirmado por Almeida (2017, não paginado) em sua conclusão, essas linhas de força da onda conservadora "estabelecem entre si conexões parciais, ora por afinidades ora por estratégia, mas todas convergem no sentido da praia”. Em razão desse quadro, da miscelânea de ideologias e pensamentos que informam o conservadorismo, a forma plural se mostra adequada. Assim como ocorre com outros conceitos, há uma diversidade de concepções, compreensões e apresentações dentro de um largo espectro: "[n]ão há conservadorismo, mas conservadorismos; da mesma forma, eles nem sempre se harmonizam, frequentemente 
competindo e entrechocando" (LYNCH, 2017, p. 315) ${ }^{132}$. Miguel (2016, p. 593) ainda aponta que

ativos na oposição ao direito ao aborto, a compreensões inclusivas de entidade familiar e a políticas de combate à homofobia, entre outros temas, os parlamentares fundamentalistas se aliam a diferentes forças conservadoras no Congresso, como os latifundiários e os detentores de armamentos, numa ação conjunta que fortalece a todos. Fora do Congresso, pastores com forte atuação política e forte presença nas redes sociais, como Silas Malafaia (da Assembleia de Deus Vitória em Cristo), dão voz à sua pauta.

Esse conservadorismo fundamentalista pretende impor no espaço público valores que concernem apenas a determinados grupos. Nas palavras de Grimm (2006, p. 106), sob fundamentalismo, "entende-se a pretensão de transformar uma determinada ética de grupo, fundada na cultura, em princípio unicamente obrigatório da ordem social, eliminando todas as reivindicações de comportamento concorrentes e reprimindo todas as outras diferentes tradições culturais". Não obstante o uso do termo cultura pelo autor alemão, pode-se tomar de empréstimo a conceituação de fundamentalismo para os propósitos deste texto. De fato, Grimm (2006, p. 103-110), no capítulo “Quanto de tolerância exige a Lei Fundamental?”, de onde se retirou a citação, escreve sobre o contexto alemão, em que a Constituição daquele país foi publicada em 1949 e não contemplou, naquele momento, o multiculturalismo e as lutas interculturais decorrentes de imigrações de representantes de diversos povos para aquele Estado. Embora ele trate, na citação, de tradições culturais, no corpo do capítulo, o autor aborda em maior parte questões religiosas. Por isso a possibilidade do uso de fundamentalismo neste (con)texto.

\section{A necessária tolerância no Estado Democrático de Direito}

Vista a crescente manifestação do conservadorismo fundamentalista no seio da sociedade brasileira contemporânea ${ }^{133}$, cumpre pensar sobre a relação entre essas vozes

\footnotetext{
${ }^{132}$ Machado (2017) prefere denominar os movimentos atuais - iniciados em 2003 e potencializados a partir de 2005 - de "neoconservadorismo fundamentalista". Segundo a autora, a inserção do prefixo neo- seria adequada, uma vez que a pretensão dos partidários dessa visão de mundo é a alteração, ou mesmo o retrocesso, dos direitos já garantidos pela Constituição da República, documentos internacionais e mesmo a legislação infraconstitucional no Brasil.

${ }^{133}$ Enquanto este texto era escrito, no findar do mês de maio e princípios de junho de 2018, o Brasil passava por momentos políticos e sociais extremamente turbulentos. Uma greve da categoria dos caminhoneiros, que durou cerca de uma semana, encerrou-se, restabelecendo alguma "ordem", ou pelo menos uma "normalidade", para a população. Em meio à deflagração e vivência da greve, diversas foram as manifestações por "intervenção militar", ainda que isto não exista constitucionalmente. É perceptível o traço conservador nesse pedido, uma vez que algumas pessoas - não poucas - preferem abrir mão dos direitos que se tem em uma democracia para viver sob a força de militares.
} 
reacionárias e a situação normativo-jurídica de determinados grupos, os quais podem ou ter negados expressamente direitos fundamentais, ou sofrer com a impossibilidade de gozo desses mesmos direitos em razão da inexistência de leis específicas. Tudo isso, decorrendo do uso da imposição institucional de visões particulares de mundo numa sociedade, como a brasileira, marcada empírica e normativamente pelo fato do pluralismo.

Essa pluralidade de visões de mundo - que, de resto, faz parte inclusive da constituição da sociedade brasileira e é fundamento normativo da República, conforme dispõe o art. $1^{\circ}, \mathrm{V}$, da Constituição - torna mais complexos não só a distribuição de justiça, mas também o reconhecimento de demandas por essa justiça. Se, por um lado, a coexistência de doutrinas abrangentes razoáveis conforma e fomenta o Estado Democrático de Direito, por outro, posturas conservadoras fundamentalistas contrapõem-se à possibilidade de se as tolerar. Conforme Grimm, "fundamentalismo é o contrário da tolerância”, pois que aquele

nega não apenas a liberdade de desenvolvimento individual, mas suprime também a autonomia relativa dos subsistemas sociais e o submete a suas máximas quase sempre religiosas, por conseguinte, ele não admite nenhuma democracia entendida como pluralista (GRIMM, 2006, p. 106).

A tolerância, então, entendida como virtude, como postura moral ou como prática política, pressupõe a pluralidade de visões de mundo e o dissenso entre elas. Segundo Rawls (2000, p. IX), "uma sociedade democrática moderna se caracteriza por uma pluralidade de doutrinas abrangentes, religiosas, filosóficas e morais", ainda que nem sempre essas doutrinas abrangentes se mostrem razoáveis.

A ideia de negação de direitos de uma minoria por parte de um grupo, cuja concepção ética de vida boa informaria as instituições do Estado, encontra-se, de fato, em tensão com o dever de tolerância. Esse dever existe como decorrência de "desacordos morais acerca dos valores últimos da vida social" de uma sociedade democrática (PETRONI, 2014, p. 96) e se caracteriza como "uma das decorrências necessárias do ideal de justiça política que fundamenta uma sociedade democrática: o princípio da igualdade de direitos políticos" (PETRONI, 2014, p. 97).

O uso que se faz da tolerância neste texto - orientado pelo liberalismo político relaciona-se a dois critérios estabelecidos por Forst (2009) no contexto de justificação discursiva da justiça: a reciprocidade e a generalidade. Segundo o autor,

Reciprocidade, nesse contexto de justificação, significa que não se reivindiquem certos direitos e recursos que são negados aos outros, e que 
nossas próprias razões (valores, interesses, necessidades) não sejam projetadas sobre as dos outros ao defendermos nossas pretensões. Deve-se estar disposto e apto a sustentar normas básicas com razões que não estejam fundadas em verdades "superiores" ou em concepções do bem que possam ser razoavelmente rejeitadas por outros com identidade ética e cultural diferentes. Ademais, de acordo com o critério da generalidade, as razões para as normas básicas devem ser reciprocamente aceitáveis e compartilháveis entre todos os cidadãos, não apenas entre os grupos dominantes (FORST, 2009 p. 22).

Assim é que tanto Forst (2009), quanto Petroni (2014), embora partindo de pressupostos diferentes, afirmam que, no Estado Democrático de Direito, minorias não devem ser dominadas pela força coercitiva estatal - normativa e materialmente - sob justificativas particulares, parciais e rejeitáveis reciprocamente de grupos detentores do poder político. Nas palavras de Forst (2009, p. 23), “os limites da tolerância são, portanto, atingidos quando um grupo tenta dominar os demais fazendo de suas visões rejeitáveis a norma geral". $\mathrm{Na}$ atualidade do constitucionalismo, a supremacia dos direitos fundamentais é a fronteira que as maiorias provisórias, estabelecidas nos centros de emanação do poder político e jurídico, não podem ultrapassar. É na esfera pública que os sentidos normativos dos direitos fundamentais são articulados e surgem (ou devem surgir) como trunfos das minorias contra as vontades majoritárias que se pretendem aniquiladoras daquelas possibilidades de compreensão. Nesse sentido:

\footnotetext{
A ideia da razão pública é a necessária articulação de conteúdos que dizem respeito aos elementos constitucionais essenciais nos fóruns políticos públicos. Então, é necessário que a estrutura de base da sociedade passe de um modus vivendi para um consenso constitucional que explicite os elementos constitucionais essenciais, constitua as possibilidades do pluralismo razoável e permita a formação de novos consensos sobrepostos (CAMILLOTO, 2016, p. 62).
}

O termo 'essenciais' em Rawls não se relaciona com qualquer concepção metafísica da filosofia, mas, sim, com o conteúdo mínimo que a constituição de cada sociedade dispõe com sendo aquele inegociável e inafastável. A tolerância, em Rawls, portanto, exige dos cidadãos o uso das capacidades do racional e do razoável sendo, ainda, vinculada ao princípio da reciprocidade.

Os procedimentos de deliberação democrática devem ser orientados pelos próprios conteúdos normativos previstos na Constituição que estabelecem as possibilidades do exercício da razão pública e os limites discursivos que os cidadãos podem utilizar nos comprometimentos intersubjetivos e dialógicos de participação na esfera pública. 
É no âmbito do processo coletivo de construção das possibilidades normativas que visam orientar a praxis que o exercício da tolerância se mostra necessário à preservação de um ambiente plural e democrático. A oferta de um discurso alinhado à perspectiva do conservadorismo fundamentalista que proponha a redução, ou mesmo a supressão, de direitos fundamentais das minorias LGBT+ constitui uma ameaça à própria manutenção do pluralismo e das bases de uma sociedade que se pretenda ser qualificada como democrática, nos termos propostos pela Constituição da República.

\section{A luta pelos direitos das pessoas LGBT+}

Dentro do cenário de pluralismo político na democracia brasileira, algumas identidades - ou seriam sujeitos? - se apresentam na luta política pelo seu desocultamento e pelo reconhecimento de seus (antigos? novos?) direitos. Saber-se se são novos ou antigos direitos passa por identificar o que legitima esses "novos" direitos. Com Wolkmer (2013, p. 138), é preciso perceber que “o processo histórico de criação ininterrupta dos 'novos' direitos fundamenta-se na afirmação permanente das necessidades humanas específicas e na legitimidade de ação dos novos atores sociais", necessidades materiais, culturais, políticas que “emergem informalmente de toda e qualquer ação social, advindas de práticas conflituosas ou cooperativas, estando ou não previstas ou contidas na legislação estatal positiva, mas que acabam se instituindo formalmente".

Especificamente para as pretensões deste trabalho, a população LGBT+ é a categoria de pessoas ou sujeitos sobre cujos "novos" direitos se pretende tratar. Embora Wolkmer seja um autor que propugna o pluralismo jurídico, em contraposição ao monismo jurídico estatal - e isso importa para este trabalho, uma vez que o foco é a disputa por positivação de direitos no âmbito formal do Estado - utilizam-se as ideias de Wolkmer (2001, 2013) para tratar dos "novos" direitos das pessoas LGBT+. O novo não significa sempre inédito. O novo direito pode ser um já existente, mas negado a um grupo social. São as lutas por satisfação das necessidades e das carências dessas pessoas pelo reconhecimento como sujeito de direito ou mesmo pela igualdade e pela liberdade para a consecução da dignidade que caracterizam a novidade do direito.

Através da análise aqui empreendida quer-se perceber a relação entre tolerância e conservadorismo fundamentalista na produção de "novos" direitos das e dos LGBT+. "Novos" direitos que se caracterizam, assim, pela articulação entre, de um lado, o reconhecimento da igualdade de tratamento pelos institutos jurídicos e da possibilidade de se 
expressarem livremente como bem entenderem e, de outro, a busca da vida digna sem discriminação no meio social brasileiro.

Com uma história que atravessa desde o desconhecimento de sua existência como categoria social e sua "invenção", passando pela criminalização e patologização de seus seres, até seu reconhecimento como sujeitos políticos e jurídicos (SEDGWICK, 2007, passim), as pessoas LGBT+ enfrentaram e enfrentam lutas dolorosas para experimentar uma vida social livre e igual. Não só no âmbito da expressão de suas subjetividades - no privado e no público - as e os LGBT+ se defrontam com a dificuldade de manifestarem suas subjetividades; também no campo do Direito, elas e eles batalham por reconhecimento e igualdade como sujeitos de direitos.

Utilizar verbos que conotam a guerra - como enfrentar, batalhar, lutar - não é casual. De fato, ao longo da história do movimento LGBT+, que se inicia por volta dos anos 1960, muitos foram os ataques psicológicos, morais e físicos sofridos por gays, lésbicas, travestis etc. Relatórios de organismos internacionais apontam que a violência contra as pessoas LGBT+ aumentou nos últimos anos. Exemplificativamente, o relatório sobre violência contras as pessoas LGBT+ da Comissão Interamericana de Direitos Humanos de 2015 (versão mais atualizada constante do site da instituição) indica que, apesar de os números não serem os mais exatos, em razão da subnotificação e da invisibilidade de crimes de LGBTfobia, diversos países reconheceram o aumento no quantitativo - e, até mesmo, na crueldade - dos delitos contras as pessoas LGBT+ (OEA, 2015, passim). Também a Organização das Nações Unidas, em relatório de 2015, enfrentou a questão da LGBTfobia e os números que ela representa (ONU, 2015, passim).

Não obstante o tema da violência sofrida pelos LGBT+ ser atual e preocupante e demandar uma posição punitiva por parte do Estado, em diversas outras áreas, como a preventiva e a promocional, por exemplo, o Direito pode atuar para consolidar a igualdade e a liberdade daquelas pessoas. Casamento e união estável homoafetivos, adoção por casais de mesma orientação sexual, doação de sangue por homossexuais, direitos previdenciários, utilização de nome social e alteração de identidade civil sem necessidade de cirurgia de readequação sexual são temas exemplificativos que tocam diretamente à subjetividade de pessoas LGBT+, que, porém, enfrentam grande resistência no Parlamento brasileiro.

Quase todos os temas mencionados foram objetos de decisões judiciais proferidas pelo Supremo Tribunal Federal e pelo Superior Tribunal de Justiça, que têm se mostrado, nos últimos 15 anos, pelo menos, sensíveis às demandas das pessoas LGBT+ por reconhecimento 
de direitos iguais aos que se submetem aos padrões heteronormativos de vivência pessoal ${ }^{134}$. Por padrões heteronormativos entende-se a forma naturalizada e pré-reflexiva de ordenar a realidade social através do binarismo de gênero, a partir do qual se incluem e excluem-se pessoas nos campos do Direito e da política. Assim, compreende-se por meio dos padrões heteronormativos a heterossexualidade como a regra segundo a qual a construção do Estado e da normatividade deste é realizada ${ }^{135}$.

Também, em âmbito administrativo das diversas esferas do Estado, direitos são assegurados, tendo como grande exemplo a possibilidade do uso de nome social. O problema apontado neste trabalho são os efeitos do discurso caracterizado como conservador fundamentalista na esfera de reconhecimento dos direitos das pessoas LGBT+. Verifica-se, nesse sentido, a morosidade, a falta de vontade, a omissão e o conservadorismo fundamentalista do Congresso Nacional, como esfera de deliberação pública sobre direitos, em legislar acerca de questões atinentes aos LGBT + .

Carrara (2010, p. 137), ao analisar a situação dos direitos sexuais no Brasil, afirma que esse "imobilismo do Congresso se deve em grande parte à influência das religiões cristãs sobre os parlamentares nas chamadas bancadas evangélicas e católicas. Tais bancadas atuam mais ou menos na mesma direção quando se trata de direitos LGBT”. Como se vê, a interferência dos parlamentares religiosos e suas instituições de afiliação no processo legislativo brasileiro afeta as questões de gênero e sexualidade de duas formas: uma, que se disse mais acima, na (tentativa de) imposição de suas concepções religiosas sobre a educação de crianças e adolescentes; a outra, na negativa de (sequer deliberar sobre) direitos de expressão de identidades desviantes do padrão heteronormativo e a vivência desses direitos em iguais condições políticas.

A situação de negação na esfera pública dos direitos das pessoas LGBT+, por grande parte do Parlamento brasileiro, se relaciona com o próprio conservadorismo do eleitor,

\footnotetext{
${ }^{134}$ No âmbito do Supremo Tribunal Federal, há as paradigmáticas decisões proferidas na ADPF 132 e na ADI 4.277, que resolveram sobre a possibilidade da constituição de uniões estáveis por pessoas do mesmo sexo; o julgamento da ADI 4.275, que definiu sobre o reconhecimento do direito à alteração de nome e sexo aos transgêneros, independentemente da cirurgia de transgenitalização, ou da realização de tratamentos hormonais ou patologizantes; e, ainda pendente de julgamento, a ADI 5.543, que discute a constitucionalidade da proibição de doação de sangue por homossexuais. Já nos julgamentos proferidos pelo Superior Tribunal de Justiça, encontram-se o REsp 889.852, que decidiu pela possiblidade de adoção de menor por casal homoafetivo; o REsp 1.183.378, que entendeu possível a conversão da união estável homoafetiva em casamento; e o REsp 395.904, que decidiu pela concessão de pensão por morte de companheiro homoafetivo.

${ }^{135}$ Para maior desenvolvimento da relação entre tolerância, heteronormatividade e pluralismo ver: CAMILLOTO; CAMILLOTO, 2017.
} 
que, por sua vez, está ancorado no conservadorismo da sociedade brasileira como um todo. Segundo Braz (2017, p. 101),

\begin{abstract}
a intolerância de nossas classes dominantes não é um fenômeno conjuntural. Historicamente elas sempre foram muito avessas a avanços sociais, mesmo aqueles que não comprometem os seus interesses econômicos. A nossa formação social nos legou uma classe dominante preconceituosa, mesquinha, egoísta, antidemocrática e violenta.
\end{abstract}

Em pesquisa realizada nos sítios eletrônicos do Senado Federal e da Câmara dos Deputados, utilizando-se os parâmetros "lgbt", "orientação sexual" e "identidade de gênero", algumas ocorrências confirmam o que se argumenta neste texto. A apresentação dos resultados aqui não se pretende exaustiva, mas se presta para demonstrar a exposição feita até o momento sobre a intenção do conservadorismo fundamentalista de impor por meio do Estado as concepções abrangentes do bem especificamente religiosas.

No site da Câmara dos Deputados, foram buscados os mencionados termos na ementa, na indexação e no inteiro teor de propostas de emenda à Constituição, projetos de lei complementar e projetos de lei, em tramitação ${ }^{136}$. No resultado, ademais dos projetos de lei que pretendem consolidar ou viabilizar direitos de minorias de gênero, aparecem os seguintes projetos de lei que caminham na direção contrária: 5.487/2016, 5.774/2016, 8.150/2017, 10.312/2018, de autoria do Deputado Professor Victório Galli (PSC/MT); 10.577/2018, do Deputado Cabo Daciolo (PATRI/RJ); 1.859/2015, dos Deputados Alan Rick (PRB/AC), Antonio Carlos Mendes Thame (PSDB/SP), Antonio Imbassahy (PSDB/BA) e outros; 3.235/2015, do Deputado Marco Feliciano (PSC/SP); 6.583/2013, do Deputado Anderson Freire (PR/PE); 7.382/2010, do Deputado Eduardo Cunha (PMDB/RJ); 9.742/2018, do Deputado Sóstenes Cavalcante (DEM/RJ); e 10.659/2018, do Deputado Delegado Waldir.

A enumeração desses projetos de lei demonstra o argumento do uso da coerção estatal por parlamentares conservadores, quando se percebe que os temas das proposições legislativas refletem a imposição de concepções de bem particulares em contraposição a liberdades públicas - como são a chamada "ideologia de gênero", o uso de banheiros por pessoas que desviam do binarismo homem/mulher, o conceito de família formada por um homem e uma mulher, a penalização da discriminação contra heterossexuais e cristãos. Além disso, todos os proponentes dos projetos acima compõem a Frente Parlamentar Evangélica do

\footnotetext{
${ }^{136}$ Pesquisa realizada em 19 de setembro de 2018. O resultado dela foi de 15 projetos de lei com o parâmetro "lgbt", 116 projetos com a expressão "orientação sexual" e 39 proposições para a busca por meio de "identidade de gênero". Alguns projetos de lei apareceram em mais de uma pesquisa, como, por exemplo, os de n. $5.487 / 2016$ e $10.577 / 2018$. 
Congresso Nacional, a chamada "Bancada Evangélica" e a Frente Parlamentar em Defesa da Vida e da Família.

Já no site do Senado Federal, a pesquisa não encontrou dados relevantes com os mesmos parâmetros utilizados para a Câmara dos Deputados ${ }^{137}$. Com a sigla "lgbt", nenhum resultado é encontrado seja para proposta de emenda constitucional, seja para projetos de lei. Por sua vez, "identidade de gênero" apresenta resultados de projetos de lei e propostas de emenda à Constituição que pretendem a garantia de direitos das minorias sexuais. Da mesma forma se dá na pesquisa com a expressão "orientação sexual”, em que as proposições legislativas em tramitação visam à proteção das pessoas que desviam dos padrões heteronormativos $^{138}$.

\section{Do diálogo possível}

A dificuldade da tolerância, no caso do embate entre conservadorismo fundamentalista no Parlamento brasileiro e (não) direitos da população LGBT+, encontra-se em admitir que os discursos baseados em concepções religiosas sirvam de fundamentação para a normatização da vida da sociedade, negando aos gays, às lésbicas, às/aos bissexuais, às travestis etc. a condição digna de parceiros livres e iguais de um Estado democrático e plural.

Neste conflito que se apresenta tão presente na vida política do Brasil, as palavras de Grimm evocam a necessidade de se conformar a discussão pública sobre direitos LGBT+ aos fundamentos, aos objetivos e aos direitos fundamentais constitucionais: "necessita-se de princípios pelos quais a solução possa se orientar. Por isso, é normal perguntar àquele documento, no qual a sociedade se pôs de acordo a respeito dos princípios de um justo ordenamento de convívio" (GRIMM, 2006, p. 104).

A justificação do uso do poder estatal para implantação de determinadas políticas, apoiadas estas em convicções particulares eticamente informadas de grupos específicos, encontra-se em contraposição às exigências de reciprocidade e generalidade acima mencionadas. O Direito exige, para a configuração de suas normas, que as razões que justifiquem a coerção estatal sejam tidas como não razoavelmente rejeitáveis, de modo que certa neutralidade atinja a produção normativa. Conforme Forst (2010, p. 105),

\footnotetext{
${ }^{137}$ Pesquisa realizada em 19 de setembro de 2018.

138 Dos resultados alcançados nessa parte da pesquisa, é possível inferir que a aparente ausência de conservadorismo nas proposições do Senado Federal decorre do bicameralismo e da competência de iniciativa legislativa. 
direitos subjetivos básicos são, portanto, garantidos por normas que 'não podem ser razoavelmente rejeitadas', que correspondem aos critérios estritos da 'reciprocidade' e 'universalidade': por conseguinte, nenhuma pessoa pode contestar reciprocamente, com boas razões, os direitos e as reivindicações justificadas de uma outra pessoa - direitos que ela mesma reivindica para si (por exemplo, o direito a um modo de vida próprio) -, e qualquer argumento que generaliza valores éticos deve ser formulado de modo a ser aceito universalmente.

Não seria, então, tolerável a postura de bancadas parlamentares conservadoras fundamentalistas de ou legislar violando direitos fundamentais de LGBT+, ou violar os direitos fundamentais LGBT+ por meio da omissão em legislar. Isso porque, em ambos os casos, o que se tem é não só a ofensa às disposições constitucionais que impedem a discriminação por "sexo" - ainda que sexo, orientação sexual e identidade de gênero não sejam sinônimos - e àquelas que impõem a igualdade - formal e material -, mas também a violação da própria democracia - entendida como uma sociedade de participação entre iguais. As manifestações, comissivas ou omissivas, de parlamentares conservadores fundamentalistas contras os direitos das pessoas LGBT+, no uso do direito de expressão e no dever-poder de legislar, afrontam o consenso social fundamental materializado na Constituição da República.

Uma das consequências que se pode extrair desse conflito entre os direitos LGBT+ (e/ou a ausência deles) e a atitude política de um Congresso Nacional infiltrado e informado por concepções éticas discriminatórias é o alijamento das pessoas LGBT+ dos direitos civis, políticos e sociais, em uma palavra, da cidadania, o que, por certo, afeta a própria essência do Estado Democrático de Direito e de uma sociedade pluralista. Por essa razão, num modelo igualitário de tolerância, "devemos impedir que [essas reivindicações intolerantes] pautem o funcionamento das instituições democráticas na medida em que não poderiam pautar o uso coletivo da coerção sem alienar uma parcela significativa de cidadãos" (PETRONI, 2014, p. 118).

Percebe-se que as sociedades ocidentais contemporâneas são caracterizadas tanto pelo constitucionalismo, quanto pelo pluralismo. O diálogo entre esses dois conceitos ocorre na permanente tensão entre os direitos fundamentais - dentre eles, a liberdade e a igualdade e as visões de mundo provisoriamente majoritárias. Os limites para esse diálogo podem ser buscados na virtude da tolerância, que exige dos participantes do processo democrático as disposições da racionalidade, da razoabilidade e do compromisso com aqueles direitos constitucionais. Não seria exagero dizer que na arena pública brasileira o discurso do conservadorismo fundamentalista torna (e tem tornado) impossível a manutenção da democracia e do pluralismo quando grupos dominantes admitem para a vida pública valores e 
atitudes que afrontam a liberdade, a igualdade e a reciprocidade. Esse discurso, vazado pelos trâmites institucionais de normatização da vida dos cidadãos, impõe aos que com eles (titulares do poder de legislar) não concordam modos de vida sustentados em verdades que só são verdades para aqueles que confessam tal ou qual filosofia ou religião.

Conforme expôs Scanlon (2009, p. 45), “os riscos envolvidos [na política de tolerância] encontram-se nem tanto na política formal das leis e constituições (ainda que possa haver nela riscos também), mas, em vez disso, na política informal, por meio da qual a natureza da sociedade é constantemente redefinida". Esta ideia da cotidianidade da política informal, vista do ponto da tolerância, implica observar o que apontado por Almeida (2017) e Nishimura (2004) sobre as manifestações do conservadorismo das pessoas nas práticas da vida social.

\section{Considerações finais}

O problema que guiou este texto foi o questionamento sobre ser possível o uso da tolerância no diálogo entre as demandas por direitos LGBT+ e o conservadorismo fundamentalista que se instalou, há alguns anos, no Congresso Nacional, inviabilizando a positivação de normas relacionadas àquela minoria. Neste ponto, já é possível sustentar a hipótese, cuja fundamentação se construiu no percurso dos argumentos expostos anteriormente, de que o dever de tolerância no Estado Democrático de Direito não admite tentativas de dominação dos sistemas político e jurídico por qualquer grupo que seja, amparado este em razões não universalizáveis e reciprocamente não justificáveis publicamente. E a negativa se ancora na característica democrática da Constituição da República, na qual se obteve um consenso sobre os direitos fundamentais de todos e todas, independentemente de suas peculiaridades ideológicas, físicas, filosóficas, religiosas ou de forma de vida - nas palavras do próprio texto constitucional, "sem preconceitos de origem, raça, sexo, cor, idade e quaisquer outras formas de discriminação", conforme dispõe o já mencionado art. $3^{\circ}$, IV. A supressão - omissiva ou comissiva - de qualquer desses direitos constitucionais por parte de uma maioria provisória não se justifica do ponto de vista moral e não passa, segundo o que se argumentou acima, pelas exigências dos critérios do dever de tolerância. Alijar alguém da condição de cidadão igual e livre para perseguir suas próprias concepções de vida boa com base em visões rejeitáveis é postura que viola a dignidade humana e, portanto, algo que não se pode tolerar. A tolerância é um dever, mas em algum momento ela deve dizer: "não toleramos os intolerantes". 


\section{Referências}

ALMEIDA, Ronaldo de. A onda quebrada - evangélicos e conservadorismo. Cadernos Pagu, Campinas, n. 50, 2017, e175001. Disponível em $<$ http://www.scielo.br/scielo.php?script=sci_arttext\&pid=S0104$83332017000200302 \& \operatorname{lng}=$ pt\&nrm=iso>. Acesso em: 29 maio 2018.

BRAZ, Marcelo. O golpe nas ilusões democráticas e a ascensão do conservadorismo reacionário. Serviço Social e Sociedade, São Paulo, n. 128: 85-103, 2017. Disponível em $<$ http://www.scielo.br/scielo.php?script=sci_arttext\&pid=S0101$66282017000100085 \& \operatorname{lng}=$ pt\&nrm=iso $>$. Acesso em 02 jun. 2018.

BONAVIDES, Paulo; ANDRADE, Paes de. História Constitucional do Brasil. Brasília: OAB Editora, 2008. $9^{\text {a }}$ ed.

CAMILloto, Bruno. Direito, Democracia e Razão Pública. Belo Horizonte: Editora D’Plácido, 2016.

CAMILLOTO, Bruno; CAMILLOTO, Ludmilla. Tolerância liberal e pluralismo: uma crítica à heteronormatividade. Revista de Direito da Faculdade Guanambi, [S.1.], v. 4, n. 01, p. 25-41, out. 2017. ISSN 2447-6536. Disponível em:

$<$ http://revistas.faculdadeguanambi.edu.br/index.php/Revistadedireito/article/view/131>. Acesso em: 28 set. 2018. doi:https://doi.org/10.29293/rdfg.v4i01.131.

CARRARA, Sérgio. Políticas e direitos sexuais no Brasil contemporâneo. Bagoas, Natal, v. 04, n. 05: 131-147, 2010. Disponível em $<$ https://periodicos.ufrn.br/bagoas/article/view/2316/1749>. Acesso em 02 jun 2018.

CARVALHO, Marcos Castro; SIVORI, Horacio Federico. Ensino religioso, gênero e sexualidade na política educacional brasileira. Cadernos Pagu, Campinas, n. 50, 2017, e175017. Disponível em <http://www.scielo.br/scielo.php?script=sci_arttext\&pid=S0104$83332017000200310 \& \operatorname{lng}=$ pt\&nrm=iso $>$. Acesso em 02 jun. 2018.

COMISSÃO INTERAMERICANA DE DIREITOS HUMANOS. Violência contra Pessoas Lésbicas, Gays, Bissexuais, Trans e Intersexo nas Américas. ISBN 978-0-8270-6594-9. Organização dos Estados Americanos, OEA/Ser.L/V/II, 2015. Doc.36/15 Rev.1.

DWORKIN, Ronald. O que é uma vida boa?. Rev. direito GV, São Paulo, v. 7, n. 2, p. 607616, Dec. 2011. Disponível em

$<$ http://www.scielo.br/scielo.php?script=sci_arttext\&pid=S1808-

$24322011000200010 \& \operatorname{lng}=$ en\&nrm=iso $>$. Acesso em 25 May 2020.

https://doi.org/10.1590/S1808-24322011000200010.

FORST, Rainer. Os limites da tolerância. Novos estud. - CEBRAP, São Paulo, n. 84: 15-29, 2009. Disponível em $<$ http://www.scielo.br/scielo.php?script=sci_arttext\&pid=S0101$33002009000200002 \& \operatorname{lng}=$ pt\&nrm=iso $>$. Acessos em 22 jun. 2018. 
FORST, Rainer. Contextos da Justiça: filosofia política para além de liberalismo e comunitarismo. Tradução de Denílson Luís Werle. São Paulo: Boitempo, 2010.

GRIMM, Dieter. Constituição e Política. Tradução de Geraldo de Carvalho; coordenação e supervisão de Luiz Moreira. Belo Horizonte: Del Rey, 2006.

HABERMAS, Jürgen. Direito e Democracia: entre facticidade e validade, volume 1. Tradução de Flávio Beno Siebeneichler. Rio de Janeiro: Tempo Brasileiro, 2003a.

HABERMAS, Jürgen. O Estado Democrático de Direito - uma amarração paradoxal de princípios contraditórios? In: HABERMAS, Jürgen. Era das Transições. Tradução e introdução de Flávio Beno Siebeneichler. Rio de Janeiro: Tempo Brasileiro, 2003b. p. 152173.

LYNCH, Christian Edward Cyril. Conservadorismo caleidoscópio: Edmund Burke e o pensamento político do Brasil oitocentista. Lua Nova, São Paulo, n. 100: 313-362, 2017. Disponível em $<$ http://www.scielo.br/scielo.php?script=sci_arttext\&pid=S010264452017000100313\&lng=pt\&nrm=iso>. Acesso em 16 maio 2018.

MACHADO, Lia Zanotta. O aborto como direito e o aborto como crime: o retrocesso neoconservador. Cadernos Pagu, Campinas, n. 50, 2017, e17504. Disponível em: $<$ http://www.scielo.br/scielo.php?script=sci_arttext\&pid=S0104$83332017000200305 \& \operatorname{lng}=$ en\&nrm=iso>. Acesso em: 29 mai 2018.

MIGUEL, Luis Felipe. Da "doutrinação marxista" à "ideologia de gênero" - Escola Sem Partido e as leis da mordaça no parlamento. Revista Direito e Práxis, v. 7, n. 3, p. 590-621, set. 2016. Disponível em: <https://www.epublicacoes.uerj.br/index.php/revistaceaju/article/view/25163/18213>. Acesso em: 02 jun 2018.

NISHIMURA, Katia Mika. Conservadorismo social: opiniões e atitudes no contexto da eleição de 2002. Opinião Pública, Campinas, v. 10, n. 2: 339-367, 2004. Disponível em $<$ http://www.scielo.br/scielo.php?script=sci_arttext\&pid=S0104$62762004000200007 \& \operatorname{lng}=$ pt\&nrm=iso $>$. Acesso em 02 jun. 2018.

NOVELINO, Marcelo. Curso de Direito Constitucional. 11. ed. rev., ampl. e atual. Salvador: JusPodivm, 2016.

PETRONI, Lucas. Temos o dever de tolerar? Rev. Bras. Ciênc. Polít., Brasília, n. 15: 95125, 2014. Disponível em: <http://www.scielo.br/scielo.php?script=sci_arttext\&pid=S0103$33522014000300095 \& \operatorname{lng}=\mathrm{en} \& n \mathrm{~nm}=\mathrm{iso}>$. Acessos em: 22 jun 2018.

PINTO, Marcos Barbosa. Constituição e Democracia. Rio de Janeiro: Renovar, 2009.

RAWLS, John. Justiça e Democracia. Tradução de Irene A. Paternot. São Paulo: Martins Fontes, 2000.

RAWLS, John. El Liberalismo Político. Traducción castellana de Antoni Domènech. Barcelona: Crítica, 2006. 
ROCHA, João Carlos de Carvalho. Liberalismo político e comunitarismo na constituição de 1988. Revista de Informação Legislativa, v. 46, n. 181: 297-311, 2009. Disponível em: $<$ http://www2.senado.leg.br/bdsf/handle/id/194908>. Acesso em: 29 mai 2018.

SCANLON, Thomas M. A dificuldade da tolerância. Novos estud. - CEBRAP, São Paulo, n. 84: 31-45, 2009. Disponível em:

$<$ http://www.scielo.br/scielo.php?script=sci_arttext\&pid=S0101$33002009000200003 \& \operatorname{lng}=$ en\&nrm=iso>. Acesso em 22 jun 2018.

SEDGWICK, Eve Kosofsky. A epistemologia do armário. Cadernos Pagu, Campinas, n. 28: 19-54, 2007. Disponível em:

$<$ http://www.scielo.br/scielo.php?script=sci_arttext\&amp;pid=S0104-

83332007000100003\&amp;lng=en\&amp;nrm=iso>. Acesso em: 30 mai 2018.

WOLKMER, Antonio Carlos. Pluralismo Jurídico: fundamentos de uma nova cultura jurídica no Direito. 3. ed., rev. e atual. São Paulo: Editora Alfa Ômega, 2001.

WOLKMER, Antonio Carlos. Introdução aos fundamentos de uma teoria geral dos 'novos' direitos. Revista Jurídica UniCuritiba, Curitiba, v. 2, n. 31: 121-148, 2013. Disponível em: $<$ http://revista.unicuritiba.edu.br/index.php/RevJur/article/view/593/454>. Acesso em: 22 jun 2018 .

Data de recebimento: 16.04 .2020

Data de aprovação: 19.08.2020 